\title{
Ética. Entre Educación y Filosofía
}

\author{
Ethics. Between Education and Philosophy
}

Ética. Entre Educação e Filosofia

Luis Radford \& Maritza Silva Acuña, Editorial Universidad de Los Andes, Santiago de Chile, 284 páginas. ISBN 9789587980516.

Mag. Alejandro Berrios Avaria*

El texto que presentan los compiladores Luis Radford y Maritza Silva es una recopilación de artículos, de diversos autores, que esbozan sus reflexiones e investigaciones organizadas desde cuatro puntos de vista, mostrando el entramado fundamental en el que muchas veces existen encuentros y desencuentros desde el binomio conformado por la matemática y la filosofía. Este libro

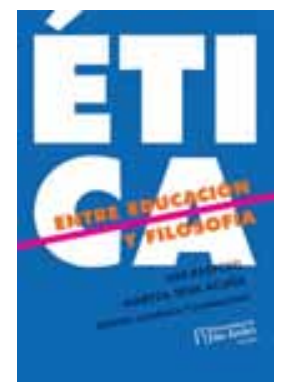
radica en la necesidad de reivindicación de una ciencia hacia la otra, pues no tiene la intención de polarizar esta distinción, más bien refuerza la idea del entramado y la cooperación mutua, ya que no es la comprobación versus la intuición, sino una colaboración que facilita la comprensión del ser humano.

Entendemos que el binomio antes declarado se encuentra tensionado en la Ética particularmente, como una perspectiva de índole social y sobre todo política, ya que permite la proyección de la filosofía y la matemática. Esto facilita comprender, desde varias subjetividades, la ética en la educación, y poder plantear y concientizar una mirada crítica a esta última. Mostrar el tránsito de un individuo particular a un

* Chileno. Profesor de Filosofía y Magíster en Educación, Universidad Católica Silva Henríquez (UCSH). Académico de la Escuela de Filosofía UCSH y editor de la Revista Foro Educacional de la Facultad de Educación de la UCSH. Contacto: aberriosa@ucsh.cl ORCID https://orcid.org/0000-0003-0286-3515 
individuo social es uno de los aportes significativos que plantea este libro, desde la tensión entre Filosofía y Matemática, a partir de la cual se forma el sujeto para una sociedad.

Asumiendo la ética un rol fundamental en el ámbito de la educación, esta se plasma en la didáctica, lo que implica que, para desarrollar un individuo social, se necesita de una educación. Para ello, es necesario preguntarse por la calidad de esa educación, por lo que en un primer momento se indaga sobre la didáctica, lo que logra visualizar y volver a colocar en la palestra la necesidad de una educación que otorgue criterios para una sociedad consciente de su estado de comunidad. Para ello se plantea el fortalecimiento de un trabajo colaborativo y comunitario desde y hacia las personas, y hacia la sociedad, y es ahí dónde se manifiesta una didáctica consciente de otros y otras.

Esto permite desarrollar una teoría de la objetivación, que se presenta y se basa en la premisa principal de que el aprendizaje es, al mismo tiempo, conocer y devenir; es decir, este no puede ser circunscrito solo al ámbito del conocimiento, sino que debe afrontar también el del ser específico de los diversos sujetos. El libro, en general, se divide en cuatro puntos fundamentales, el primero es "entre la Filosofía y la Educación"; el segundo "entre la Educación y la Filosofía”; el tercer aparatado lleva por título "la Ética de la educación" y el último es una reflexión académica, que sirve de colofón al texto general.

\section{Primera parte}

El primer apartado tiene la misión de abrir los fuegos a través de la ética, que se presenta como el vínculo de unión y reflexión entre la filosofía y la educación, con un análisis muy pertinente desde la labor pedagógica. Este es, precisamente, el gran aporte y la proyección pedagógica. En el primer artículo se indica que el espacio educativo es una riqueza de subjetividades que ayudan a una concientización de otros, valorando el espacio común que es el aula. Dicho espacio puede mostrarse como una sensibilidad ética y el hecho educativo se basa en el comprender y comprenderse como personas.

En el segundo artículo se pone el foco en la educación ética desde el cuerpo, desde una sensibilidad de las artes, exponiendo la danza como una oportunidad de comprender nuevas nociones de "corpo- 
reidad" y de "habitar". Esta nueva relación pedagógica que presenta la noción de corporeidad, permite una apropiación del individuo en comunidad. El tercer artículo es una propuesta estética para la educación, lo que enriquece la concepción misma del proceso educativo. En otras palabras, se busca dar respuesta a la pregunta ¿qué entendemos por educación? Y, desde esa estética, se plantea al tacto como una herramienta que permite reconocer una contemplación que lleva a una ética, tanto en el proceso educativo como en la formación de profesores.

\section{Segunda parte}

En este apartado la relación se invierte, y el debate se sitúa entre educación y filosofía, presentadas no como situaciones idénticas, sino simétricas, tal como se menciona en el prólogo. Comienza esta sección poniendo en tela de juicio la ética de la matemática, revisando las repercusiones que esta tiene en la educación y la sociedad, y atisbando una sobrevaloración de la ciencia, al punto de catalogarla como un monstruo, ya que se transforma en un impedimento. Esto porque, en algunos casos, condiciona un modo de ver exitoso al otro desde la mirada del aprendizaje de las matemáticas, que, a su vez, pone en tela de juicio las herramientas que éstas proporcionan, particularmente en el uso de las tecnologías, ocultando la realidad social. El artículo cierra con una mirada propositiva de las matemáticas.

El segundo artículo presenta a la ética en relación con la teoría de la objetivación. Se analiza aquí la dimensión ética de una teoría educativa, y cómo ésta permite la construcción de saberes. Todo esto desde una mirada del encuentro y, sobre todo, una mirada comunitaria, que permite obtener una nueva mirada del individuo y de la sociedad, y del modo en que estas se relacionan. A partir del análisis de Thomas Hobbes, como postura controladora y reguladora, se retoma esta misma mirada, que, a su vez, permite la realización del individuo, por lo que es una tensión personal y social, a la vez. Esto se trastoca desde el punto de vista de la objetivación, ya que es ahí, en el encuentro y enfrentamiento con el entorno, donde se construye el individuo. Esto afirma que, comprendiendo la alteridad, se vislumbra la escuela como un espacio que brinda la posibilidad de entender a otras personas. 


\section{Tercera parte}

En esta se aborda el problema de la ética en la educación. Se abre un camino significativo, pues se trata la cuestión de cómo la ética se revela y se especifica en la educación. En el primer artículo se presentan los principios y orientaciones de la evaluación. Ciertamente, dentro del proceso de constante evaluación y con una mirada crítica de la educación, es pertinente tener principios claros, que guíen e iluminen dicho proceso. Entendiendo la evaluación como una puesta en práctica de juicios de valor, se hace necesario que dichos juicios tengan un respaldo, dilucidando los códigos de la ética de las diversas profesiones y más aún, en el ámbito de la docencia. En este capítulo el autor da claros signos de los elementos que debe tener una evaluación, desde la concepción de la Academia de Deusto, hasta la American Evaluation Association, concluyendo que siempre se debe responder por las decisiones asumidas frente a los diversos destinatarios de la evaluación.

El segundo artículo de este apartado se centra en las implicancias éticas del quehacer docente, esto es, en asumir críticamente las problemáticas que surgen en el sistema educativo. La exposición avanza desde tres puntos argumentativos: inicia con la argumentación de las corrientes filosóficas, para pasar a los elementos objetivos del docente y terminar en los elementos subjetivos, llegando a plantear que "ser docente exige una constante tensión ética". Desde una mirada institucional, se puede decir que no se lleva a cabo una actualización frente a la vorágine que plantea la sociedad, en conjunto con los estudiantes, pues para estos es necesario crear un modelo o un criterio que permita generar un pensamiento autónomo. El autor reflexiona apostando por el cuidado del otro desde una corresponsabilidad en un contexto específico, para lo que coloca al profesor como centro de innovación y como responsable de los espacios que permean la educación y la ética de forma transversal.

El tercer artículo aborda la formación docente y muestra cómo los estudiantes de pedagogía conforman y forman su identidad docente desde los diversos saberes. Se comienza describiendo los múltiples conocimientos de los docentes y su diversidad, para terminar, destacando la nobleza que implica ser profesor o enseñar desde una valoración y desvaloración sistemática, esto es, valorando las narrativas que per- 
miten comprender y comprenderse desde los individuos en su propia formación docente. El artículo concluye afirmando que la adquisición de saberes se hace desde la conversión, desde otros, y que la comprensión ayuda a ejercer el saber pedagógico. Todo lo anterior para generar la articulación de una identidad docente.

El cuarto artículo presenta cómo las interacciones sociales se realizan desde las actividades matemáticas. Comenzando con la ética en el sistema educativo, y reflexionando desde las actividades matemáticas escolares, para identificar elementos de discusión que ayuden a una socialización. Nuevamente el peso de la reflexión esta en la ética de la objetivación y la conciencia de la alteridad. Se muestra así la tensión en las actividades docentes desde el individualismo, cuando se suscita un trabajo colectivo que da cuenta de una colaboración sinérgica. Por su parte, el quinto artículo muestra la presencia de la dimensión ética en los modelos pedagógicos de los docentes de matemáticas que forman personal del área de la salud. Se levanta aquí la información de los modelos pedagógicos, a partir de una ética comunitaria y de un modelo pedagógico matemático. Se concluye que la práctica de los profesores debe orientarse a una ética comunitaria, lo que debe ser declarado y gestionado. Esto permitirá comprender un aseguramiento de la calidad desde un plan de mejora continua, que permita establecer en el modelo pedagógico una ética comunitaria.

\section{Cuarta parte}

El primer y único artículo de este apartado aglutina todo lo antes expresado, y presenta la duda que genera la crisis ética en el campo de la educación. Todo esto haciendo un análisis del texto desde su propia realidad y conocimiento, lo que permite develar la unidad de este y de cómo se va formando la reflexión pedagógica y la práctica desde la ética.

El libro, en general, nos ayuda a comprender la complejidad de la educación, más aún la tensión que se presenta entre filosofía y matemática, y el modo en que la ética puede devolver la mirada social y comunitaria que siempre ha tenido la educación. 